\title{
La era de las aceleraciones: crisis de Europa y su papel en el futuro
}

\section{Ramón Barinaga Osinalde}

rbarinaga@movistar.es
Gaur egun bizi dugun garaian teknologiaren, globalizazio ekonomikoaren eta gizakiok aldaketa klimatikoan dugun eragina bizkortzen ari da. Produkzioan, kontsumoan, ingurumenari konektatzeko eta eragiteko modu berriak sortzen ditu aldaketa horren abiadurak; eta beste egokitzapen batzuen artetik, babes sozialeko sare eta gobernu-erregulazio berriak garatu behar dira herritarrek abiadura horren probetxu izan dezaten eta eraginik okerrenak orekatu ahal izateko. Hori izango da ziurrenik gaur egungo gobernagarritasunaren erronkarik garrantzitsuena. Botere politikoak merkatuarengan duen eraginaren galerarekin bat gertatu da aurretik aipatutako hori guztia, gizakion jarduerak ingurumenean eta desberdintasun-mailan eragina hazten den garai batean; eta eredu iragarle matematikoen erabileraren maiztasuna hazten ari da, baina desberdintasuna areagotu nahi ez bada, balioak gehitu beharra izango dute eredu horiek.

\section{GAKO-HITZAK:}

Bizkortzea, desberdintasun-maila, ongi komuna, big data, birbanaketa, Europa.
Estamos viviendo una época en la que se está produciendo una aceleración de la tecnología, de la globalización económica y de la influencia de la actividad humana en el cambio climático. La velocidad del cambio, que nos sumerge en nuevas formas de producir, consumir, conectarnos e impactar en la naturaleza, exige, entre otras adaptaciones, desarrollar nuevas redes de protección social y regulaciones gubernamentales que permitan a los ciudadanos aprovechar al máximo estas aceleraciones y mitigar sus peores efectos. Ello constituye, posiblemente, el principal reto de gobernabilidad actual. Esto ocurre en un mundo en el que el poder político ha perdido influencia respecto del mercado, incrementándose el impacto medioambiental de la actividad humana y la desigualdad, y en el que la profusa y creciente utilización de modelos matemáticos predictivos reclama la incorporación de valores a ellos, si no se quiere profundizar en la desigualdad. En el marco europeo, las diversas crisis que afectan a la Unión Europea y su posible papel en el futuro, si se pretende su continuidad, plantearán probablemente la necesidad de avanzar en la integración y dimensión social del proyecto europeo.

\section{PALABRAS CLAVE:}

Aceleración, desigualdad, bien común, big data, redistribución, Europa. 


\section{Introducción}

Finalizando la segunda década del siglo XXI se está produciendo una aceleración de la tecnología, de la globalización económica y de la influencia de la actividad humana en el cambio climático, lo que exige desarrollar, entre otros, nuevos sistemas de formación, gestión, y protección social, para aprovechar las oportunidades y minimizar los efectos negativos de este nuevo momento. La profusa utilización de modelos matemáticos predictivos, de creciente influencia en todos los órdenes de la vida, reclama la incorporación de valores a fin de evitar los efectos perniciosos de su manejo en cuanto a la igualdad de oportunidades, en un mundo crecientemente desigual.

En este contexto general, Europa se enfrenta a diversas crisis a partir de las que se plantean escenarios de futuro y posibles vías de solución, que pasarían por una mayor integración y el refuerzo de su dimensión social. Este artículo recogerá las opiniones de diversos autores sobre estas cuestiones.

\section{La era de las aceleraciones}

En su libro Gracias por llegar tarde (Friedman, 2018), Thomas L. Friedman, escritor y periodista estadounidense, columnista sobre política internacional, globalización y tecnología en el The New York Times, plantea el argumento central de que las aceleraciones que se están dando estos últimos años, y en particular a partir de 2007, en el mercado, en la naturaleza y en la tecnología, nos sitúan en una "era de las aceleraciones" que transforma casi todos los aspectos de la vida moderna. En esta nueva época, puede decirse que la velocidad del cambio supera la capacidad de adaptación con el resultado de una "dislocación”, aquella situación en la que "el entorno está siendo tan rápidamente alterado que todo el mundo siente que no puede seguir el ritmo".

Para Friedman "existe una disparidad entre el cambio en la velocidad de cambio y nuestra capacidad para desarrollar sistemas de aprendizaje, sistemas de capacitación, sistemas de gestión, redes de protección social y regulaciones gubernamentales que permitan a los ciudadanos aprovechar al máximo estas aceleraciones y amortiguar sus peores efectos". Esta disparidad, añade, "se encuentra en el centro de gran parte de la inestabilidad que afecta en estos momentos a la política y a la sociedad, tanto en países desarrollados como en desarrollo. Esto posiblemente constituya actualmente el reto de gobernabilidad más importante para todo el mundo" (Friedman, 2018: 42-43). Veamos algunas de las principales características de las referidas tres aceleraciones.

\subsection{La aceleración tecnológica}

"Entre 2000 y 2007 entramos en un mundo donde la conectividad era rápida, gratis, sencilla y ubicua, y manejar la complejidad se volvió algo rápido, gratuito, sencillo e invisible". No solo era posible llegar a gente a la que nunca se había llegado y que ellos llegaran a ti, sino que se podían hacer todo tipo de cosas asombrosas y complejas con un solo toque. La rapidez es la evolución natural de juntar toda esta tecnología y luego diseminarla por todas partes. (Friedman, 2018: 122).

Es así como, la nube, como generalmente se la conoce, o la supernova, en expresión acuñada a estos efectos por Friedman "está creando una emisión de energía que está ampliando todas las diferentes formas de poder -el poder de las máquinas, de las personas, del flujo de ideas, y de la humanidad en conjunto- a unos niveles sin precedentes. Esta tecnología que incrementa el poder de las máquinas haciéndolas que "piensen", expande y acelera el "poder de los flujos" de conocimiento, ampliando enormemente el "poder de uno" y desde luego "el poder de muchos" - el ser humano se ha convertido en una fuerza de la naturaleza, una fuerza que está perturbando y cambiando el clima y los ecosistemas de nuestro planeta [...]-, ampliando la capacidad de hacer el bien o el mal a una velocidad y con un alcance nunca vistos en la historia de la humanidad" (Friedman, 2018: 115-116).

El 14 de febrero de 2011 fue el año en que un ordenador diseñado por IBM fue capaz de vencer en un célebre concurso de tres días de la televisión americana Jeopardy a los mejores campeones humanos, inaugurando la "era cognitiva" de la informática, superando las anteriores etapas, por orden de aparición, de la "tabulación” y de la "programación".

Como señala el columnista del New York Times, “los sistemas cognitivos [...] son 'probabilísticos', lo que significa que han sido diseñados para adaptarse, comprender y asimilar la complejidad e imprevisibilidad de la información desestructurada". Pueden “leer” textos, “ver” imágenes y “oír” un discurso natural. E interpretan esa información, la organizan y ofrecen explicaciones sobre lo que significa junto con la justificación para sus conclusiones. No ofrecen respuestas definitivas, De hecho no "saben" la respuesta. Más bien están diseñados para sopesar información e ideas de múltiples fuentes, razonar y luego plantear hipótesis para su consideración”. En base a algoritmos, “los sistemas cognitivos clasifican lo que creen que son las respuestas correctas, asignándoles grados de confianza a todas" (Friedman, 2018: 130-132).

\subsection{La aceleración de la globalización}

Friedman defiende que en este inicio del siglo XXI la globalización, más allá de una medida del comercio de bienes tangibles, servicios y transacciones financieras, debe ser entendida como la capacidad de cualquier persona o empresa de competir, conectar, intercambiar o colaborar globalmente. $Y$ 
para este autor, la globalización así entendida está estallando. "La globalización medida por flujos se ha disparado, transmitiendo información, ideas e innovación por todo el mundo y ampliando la participación en la economía global” (Friedman, 2018: 157).

Así, para algunos expertos estaríamos asistiendo al "gran cambio", entendido como "un momento en el que estamos pasando de un largo periodo en la historia en que las reservas eran la medida de la riqueza y el motor de crecimiento, [...], a un mundo en que la fuente más relevante de ventaja comparativa será cuán abundantes y numerosos sean los flujos que pasen por tu país o comunidad, y lo bien capacitados que estarán tus ciudadanos-trabajadores para poder sacar provecho de ellos". (Friedman, 2018: 168) De esta manera, "hoy en día, para tener éxito, hemos de actualizar continuamente nuestras reservas de conocimiento participando en los flujos relevantes de nuevos conocimientos" (Friedman, 2018: 170).

Historiadores como William H. McNeill autor del El Auge de Occidente, citado por Friedman en su análisis sobre cuál es el motor de la historia, o qué factor influye más que ningún otro en el avance de la historia, llegó a señalar que "el factor principal que promueve cambios sociales significativos es el contacto entre desconocidos que poseen destrezas nuevas y desconocidas". En esta línea, añade Friedman: "De la misma manera que el clima está cambiando y el tiempo meteorológico circula de forma diferente, la globalización está cambiando la velocidad a la que circulan y cambian las ideas. Y ahora esto está planteando un reto serio en cuanto a adaptación” (Friedman, 2018: 192-195).

En este mundo tan rápidamente cambiante, Friedman subraya la ambivalencia de la globalización que "siempre ha consistido en dos extremos opuestos: puede ser increíblemente democratizadora y puede concentrar un poder increíble en multinacionales gigantes; y puede ser individualizadora (las voces más pequeñas pueden ahora oírse por todas partes) e increíblemente homogeneizadora, con grandes marcas capaces de inundar todo en cualquier parte. Puede otorgar un poder increíble, como las pequeñas empresas y particulares capaces de crear una empresa global de la noche al día, con clientes, proveedores y colaboradores globales. Y puede quitar poder, porque las grandes fuerzas pueden surgir de la nada y destrozar tu negocio mientras tú ni siquiera sospechas que estuvieran en el mismo sector que tú. Hacia qué lado se incline dependerá de los valores y las herramientas que todos aportemos a estos flujos" (Friedman, 2018: 199-202).

\subsection{La aceleración del cambio climático}

La intervención humana en el planeta Tierra, especialmente acusada en los dos últimos siglos y crecientemente acelerada, está haciendo que los expertos señalen un cambio de era en el estaríamos pasando del Holoceno -últimos 10.500 años- en el que se ha desarrollado la especie humana, a un "antropoceno", en el que el impacto de la actividad humana sobre nuestro hábitat es muy fuerte.

"Nosotros como especie somos ahora una fuerza de la naturaleza, en la naturaleza y sobre la naturaleza, [...], a partir de la década de los sesenta y setenta, cuando la Revolución Industrial alcanzó muchos puntos nuevos del globo, en concreto China, la India y Brasil, las poblaciones y las clases medias empezaron a expandirse simultáneamente, [...], a partir de la primera década del siglo XXI, la supernova (la nube) creó otra oleada de fabricación industrial, urbanización, telecomunicaciones, turismo y comercio global”. La combinación de todas estas tendencias ha empezado a ejercer presión en cada uno de los principales ecosistemas de la Tierra y sus cañerías, en una medida nunca vista en la historia del planeta. El resultado: nuestro estilo de vida en el Jardín del Edén corre peligro.

Ante estas tres aceleraciones, Friedman aboga por recuperar el espíritu de cohesión, comenzando por las comunidades locales, diseñando estrategias público-privadas que aúnen iniciativas surgidas en la base con otras que provengan de las instituciones, para dar formación y oportunidades a todas las personas en el nuevo escenario, y en definitiva crear nuevas redes de protección social y regulaciones gubernamentales para que las personas puedan aprovechar las oportunidades que brinda el nuevo escenario y mitigar sus peores efectos.

\section{Esfera pública, expulsiones y 'big data'}

\subsection{La degradación de la esfera pública}

En su libro Decir NO no basta (Klein: 2017), Naomi Klein, reconocida periodista estadounidense, activista a favor del medio ambiente y galardonada con el Premio de la Paz de Sidney, hace un análisis de la actual Administración americana, que como ella misma señala es susceptible de aplicación general a otras zonas del mundo occidental, y nos dice que "sobre todo, encarna un proyecto ideológico de libre mercado que sigue siendo poderoso - que abrazan por igual los partidos de centro y los conservadoresy que ha declarado la guerra a todo lo público o comunal”. Añade que la actual Administración americana "[...] no habría sido posible sin la degradación del concepto de esfera pública en su conjunto, que lleva décadas difundiéndose. Nunca hubiera tenido lugar de no haber calado la idea de que "el Gobierno no es la solución, es el problema”, en las célebres palabras de Ronald Reagan.

Para Klein, “desde hace ya una década larga, el flanco ideológico e intelectual del proyecto neoliberal atraviesa una profunda crisis. En 2016, Credit Suisse ha calculado que la riqueza total que hay en el mundo es de aproximadamente 256.000 millones de 
dólares [...], repartidos de forma abrumadoramente desigual". "Mientras que la mitad más pobre de la población posee en conjunto el $1 \%$ de la riqueza global, el $10 \%$ más rico es dueño del $89 \%$ de todos los activos del mundo". "Y eso explica que apenas quede gente mínimamente seria dispuesta a argumentar, sin que les entre la risa, que dar más a los ricos sea la mejor manera de ayudar a los pobres". (Klein, 2017: 66).

A lo largo de las últimas décadas "entraron en franco declive las instituciones fundamentales que antes daban a los individuos un sentimiento de comunidad y de identidad compartida: barrios con gran cohesión social [...]; grandes locales de trabajo que encerraban la promesa de un empleo para toda la vida; [...] religiones organizadas; movimientos políticos y sindicatos sólidamente asentados en relaciones interpersonales; medios de comunicación al servicio del interés público, que luchaban por unir a las naciones mediante un diálogo de todos".

Con su imperfección, esas instituciones y tradiciones ofrecían al ser humano lo que este nunca deja de anhelar: comunidad, interrelación, la sensación de tener una misión más grande que nuestros atomizados deseos inmediatos. Esas dos tendencias -el declive de las instituciones comunitarias y la expansión de las marcas corporativas en nuestra cultura- explican el creciente vacío que el consumismo no sacia y supone la "fórmula perfecta para el consumo sin fin y la auto mercantilización perpetua a través de las redes sociales, y es una catástrofe para el planeta, que no puede sostener esos niveles de consumo".

Para esta escritora estadounidense "el cambio climático hace saltar por los aires el andamio ideológico en el que se apoya el conservadurismo contemporáneo. Por ello [...] detener el calentamiento global [...] es ya una cuestión de supervivencia colectiva de la humanidad". En su opinión, las sociedades tenemos la opción de "unirnos para hacer frente a una amenaza común y grave, y dar un salto evolutivo. [...], podemos dejarnos pasmados a nosotros mismos si nos unimos, nos concentramos, perseveramos". (Klein, 2017: 303).

\subsection{Un mundo generador de expulsiones}

Saskia Sassen, socióloga, economista y filósofa, en su libro Expulsiones. Brutalidad y complejidad en la economía global" (Sassen, 2015) expone su hipótesis central según la cual "el paso del keynesianismo a la era global, de privatizaciones, desregulación y fronteras abiertas para algunos, implicaba un pasaje de una dinámica que atraía a gente hacia el interior a otra dinámica que empuja gente hacia fuera". Analiza lo que denomina "el filo del sistema", "el lugar en las condiciones generales adoptan formas extremas precisamente porque es el lugar de la expulsión o la incorporación" (Sassen, 2015: 237). Sassia ve hoy nuevas lógicas sistémicas surgiendo de la descomposición de la economía política del siglo XX. Esa descomposición se inició en la década de 1980.

En su opinión, "el mundo que empezamos a construir al otro día de la devastación, empezando en Occidente en particular al término de la Segunda Guerra Mundial, era un mundo impulsado por una lógica de inclusión, por un esfuerzo concertado por traer a los pobres y los marginados a la corriente política y económica principal. Los supuestos keynesianos, igualitarios y de base nacional que subyacían a ese proyecto de construir una sociedad justa empezaron a desmoronarse hacia el final del siglo. Hemos tardado mucho en comprender y dar nombre a las fuerzas y las dinámicas que han surgido del polvo".

"Hemos caído bajo el influjo de una concepción peligrosamente estrecha del crecimiento económico. El crecimiento, desde luego, era esencial para el proyecto del Estado de Bienestar, pero también era un medio de impulsar el interés público, de aumentar una prosperidad que sería compartida por muchos, aunque por algunos mucho más que por otros. En contraste con eso, hoy nuestras instituciones y nuestros supuestos están cada vez más al servicio del crecimiento económico corporativo. Esa es la nueva lógica del sistema, [...] cualquier cosa o cualquier persona, ya sea una ley o un esfuerzo cívico, que dificulte el lucro, corre el riesgo de que la hagan a un lado, de que la expulsen".

Hoy, "las corporaciones tienen notables herramientas nuevas a su disposición: matemáticas y comunicaciones avanzadas, maquinas que literalmente mueven montañas, libertad de movimientos y de maniobra global que les permite ignorar o intimidar a gobiernos nacionales, y cada vez más instituciones internacionales que imponen a todo el mundo el cumplimiento de sus agendas" (Sassen, 2015: 240).

Sassia ve en los sectores económicos distintos, manifestaciones en la superficie de lo que en realidad serían "unas pocas capacidades técnicas u organizacionales transformativas de gran envergadura que subyacen a todas esas diferenciaciones superficiales, [...], un ejemplo en grande serían las innovaciones financieras avanzadas que son capaces de cortar transversalmente una variedad de sectores económicos y someterlos a su propia lógica, cualquiera que sea su contenido, desde deudas intangibles hasta grandes edificios. Otro ejemplo es el aumento a escala global de nuestra destrucción ambiental".

Esta autora insiste en que "el filo del sistema hoy es un espacio de expulsiones". "Lo que está en juego en todos esos procesos es la cuestión de la membresía y la participación constitutiva". ¿Cuáles son los espacios de los expulsados? Para las mediciones estándar de nuestras economías y estados modernos son invisibles, Pero deberíamos 
hacerlos conceptualmente visibles. Cuando proliferan las dinámicas de expulsión, ya sea en la forma de la economía encogida de Grecia, las élites predatorias de Angola o el crecimiento de los desempleados a largo plazo o los encarcelados en prisiones con fines de lucro en Estados Unidos, el espacio de los expulsados se expande y se va haciendo cada vez más diferenciado. "Son, en potencia, los nuevos espacios para hacer: hacer economías locales, historias nuevas y nuevas formas de membresía" (Sassen, 2015: 248-249).

\section{3. 'Big data' y desigualdad: modelos matemáticos y decisiones morales}

Cada vez más, nuestras vidas, aun sin que seamos conscientes de hasta qué punto, están siendo orientadas por modelos matemáticos, por algoritmos, que analizan la información recabada de grandes conjuntos de personas, aspecto este novedoso y característico de la era digital, y ayudan a las empresas a tomar decisiones que nos afectan en todos los órdenes de la vida.

Por ello, en su libro Armas de Destrucción Matemática” (O’Neill: 2017), Cathy O’Neill, doctora en Matemáticas por la Universidad de Harvard y reconocida científica de datos, muestra su preocupación por el poder de las técnicas matemáticas de análisis de datos. En su propia experiencia académica y laboral en diversos ámbitos en Estados Unidos, desde el ámbito financiero hasta movimientos alternativos, ha observado que estas técnicas son utilizadas de hecho para segmentar a la población, categorizarla en función de determinados parámetros y ayudar a maximizar el beneficio de las empresas sin prestar atención a los valores cuya utilización implica.

“Los procesos del big data codifican el pasado. No inventan el futuro. Para inventar el futuro hace falta imaginación moral y eso es algo que solo los seres humanos pueden ofrecer. Debemos integrar de forma explícita mejores valores en nuestros algoritmos y crear modelos de big data que sigan nuestro ejemplo ético. $Y$ a veces eso significa dar prioridad a la justicia antes que a los beneficios" (O’Neill, 2017: 252-253).

“¿Y cómo empezar ahora a regular los modelos matemáticos que dirigen cada vez más nuestras vidas? Yo sugeriría que el proceso comenzara con los programadores que crean los modelos. Al igual que los médicos, los científicos de datos deberían hacer un juramento hipocrático centrado en los posibles abusos y malinterpretaciones de sus modelos". Pero esta autora es de la opinión de que la autorregulación y unos valores sólidos solo contendrán a los escrupulosos. Para eliminar las "armas de destrucción matemática” (ADM) debemos ir más allá de unas meras buenas prácticas en el gremio de los datos: las leyes también deben cambiar. Y para que eso ocurra debemos reevaluar cómo medimos el éxito. En la actualidad el éxito de un modelo suele medirse en términos de beneficios, eficiencia o tasas de morosidad. Casi siempre se mide con algo que se pueda contar. Pero ¿qué deberíamos contar?

"Y lo mismo suele ocurrir con la justicia y el bien común en los modelos matemáticos. Son conceptos que radican únicamente en la mente humana y se resisten a la cuantificación [...]; parece demasiado difícil. No obstante, tenemos que imponer valores humanos en estos sistemas, aunque sea a costa de la eficiencia [...] las matemáticas deben ser nuestras herramientas, no nuestras armas". (O’Neill, 2017: 256)

En opinión de O’Neill debemos investigar el mundo de las armas de destrucción matemática y auditarlas. "Ya están en marcha algunos movimientos para auditar algoritmos. En Princeton, por ejemplo, los investigadores han lanzado un proyecto sobre responsabilidad y transparencia en la web. Han creado robots de software que se disfrazan en Internet como si fueran personas de todo tipo: ricos, pobres, hombres, mujeres, o personas con problemas de salud mental. Los investigadores estudian el tratamiento que reciben estos robots y así pueden detectar los sesgos existentes en los sistemas automáticos, desde los motores de búsqueda hasta las paginas web de búsqueda de empleo. Se están lanzando iniciativas similares en universidades como Carnegie Mellon o el MIT. El apoyo académico a estas iniciativas es crucial. Al fin y al cabo, para vigilar las ADM necesitamos a personas que tengan las competencias necesarias para construirlas. Sus herramientas de investigación pueden replicar la inmensa escala de las ADM y encontrar conjuntos de datos que sean lo suficientemente grandes como para revelar los desequilibrios y las injusticias incrustados en los modelos".

En esta cuestión, “el Gobierno [...] tiene que jugar un importante papel regulatorio, igual que hizo cuando se enfrentó a la Primera Revolución Industrial. Puede empezar, en primer lugar, por adaptar y aplicar las leyes que ya existen. En segundo lugar, la legislación debe ampliarse y cubrir los nuevos tipos de empresas de concesión de préstamos, como Lending Club, que utilizan calificaciones electrónicas modernas para predecir el riesgo de impago de los préstamos. No debería permitírseles operar en las sombras".

También es necesario actualizar la Ley sobre Estadounidenses con Discapacidades (ADA, por sus siglas en inglés), que protege a las personas con problemas mentales de la discriminación en el lugar del trabajo. El texto de la ley prohíbe en la actualidad la realización de exámenes médicos dentro del proceso de selección, pero es necesario actualizarlo para que prohíba también los test de personalidad, las calificaciones de salud y las calificaciones de reputación del big data. Y todos se escabullen de la aplicación de la ley y no deberían hacerlo. 
En la actualidad se ha comenzado a debatir la ampliación de la protección de la ADA "para que prohíba también los resultados de las 'predicciones' de salud que llegarán en el futuro, Es decir, que no deberían negársele oportunidades de empleo a una persona porque su análisis genético muestre que tiene un alto riesgo de desarrollar cáncer de mama o Alzheimer".

“También debemos ampliar la cobertura de la Ley de Transferibilidad y Responsabilidad de los Seguros Médicos, que protege nuestra información médica, para que cubra los datos médicos que están recopilando actualmente las empresas sobre sus empleados, las apps de salud y otras empresas de big data". Para esta matemática estadounidense, el objetivo es utilizar los modelos matemáticos para ayudar a la sociedad, en definitiva, crear un modelo para el bien común, como en el caso de su colaboración con el Departamento de Servicios Humanos y de Vivienda de Nueva York en su análisis sobre la población sin techo y la identificación de servicios para dicha población.

"Aunque el big data, si se maneja con prudencia, puede facilitar la comprensión profunda de muchos fenómenos, muchas de sus conclusiones serán disruptivas. Al fin y al cabo, el objetivo del big data es encontrar patrones que son invisibles al ojo humano [...]. Al estudiar la economía de los datos, encuentro montones de modelos matemáticos que podrían utilizarse para hacer el bien y otros tantos con el potencial de ser grandiosos, como en el caso del trabajo de Mira Bernestein, doctora en Matemáticas por Harvard que creó un modelo para investigar la esclavitud en empresas de manufactura, o modelos para el bien común como el utilizado en el campo del trabajo social para identificar los hogares en los que es más probable que los niños sufran malos tratos" (O’Neill, 2017: 268).

La utilización de modelos matemáticos "se multiplicará en los próximos años y valorarán nuestro riesgo de sufrir osteoporosis o un infarto, se lanzarán en picado para ayudar a los alumnos que tengan dificultades con Cálculo II e incluso harán una predicción de qué personas tienen mayor probabilidad de sufrir caídas graves con secuelas permanentes. Muchos de estos modelos, al igual que algunas de las ADM que hemos comentado, llegarán con la mejor de las intenciones, pero deben garantizar también la transparencia y publicar tanto los datos de entrada que utilizan como los resultados de su segmentación: y deben someterse a auditorias. Al fin y al cabo son motores muy potentes. No
"Los datos no van a desaparecer, ni tampoco los ordenadores [...] y aún menos las matemáticas. Los modelos predictivos son las herramientas de las que dependeremos cada vez más para dirigir nuestras instituciones, desplegar nuestros recursos y gestionar nuestras vidas. No obstante [...] estos modelos no se construyen únicamente con datos, sino también con las decisiones que tomamos sobre cuáles son los datos a los que debemos prestar atención -y qué datos dejaremos fuera-. Y esas decisiones no se refieren únicamente a cuestiones logísticas, de beneficios o eficiencia, sino que son fundamentalmente decisiones morales.
"Si nos retiramos y tratamos los modelos matemáticos como si fueran una fuerza neutra e inevitable, como la meteorología o las mareas, estaremos renunciando a nuestra responsabilidad. Y el resultado, como hemos visto, son ADM que nos tratan como piezas de una maquinaria en el lugar de trabajo, que excluyen a posibles empleados y que se dan un festín con las desigualdades. Debemos trabajar juntos para vigilar, dominar y desarmar estas ADM. Espero que pasen a la historia, al igual que ocurrió con las terribles minas de carbón de hace un siglo, como las reliquias de los albores de esta nueva revolución, antes de que aprendiéramos a introducir la justicia y la rendición de cuentas en la era de los datos. Las matemáticas se merecen mucho más que las ADM, y la democracia también" (O’Neill, 2017: 269).

\section{En torno a la desigualdad}

La constatación de una creciente desigualdad no parece un hecho que haya que admitir como si se tratase de algo irremediable. Genera sufrimiento y plantea dudas sobre la sostenibilidad de las sociedades en su interior y a nivel planetario, y nos hace preguntarnos sobre el propio futuro de la humanidad. Distintos autores nos ofrecen sus puntos de vista respecto a la desigualdad.

\subsection{Se puede influir en la desigualdad}

En su libro The Anatomy of Inequality (Molander, 2016) el economista sueco Per Molander nos dice que ya en textos de en torno a cuatro mil años de antigüedad de la civilización sumeria se recogía la preocupación de las personas que entonces vivían en esa parte de Mesopotamia por las situaciones de desigualdad, por la opresión del hombre sobre el hombre, y se invocaba a la diosa Nanshe "que proteja al huérfano, que proteja a la viuda, que brinde justicia al pobre". Propone en su obra un análisis de la desigualdad en base a tres cuestiones.

La primera pregunta que se hace es "¿Por que todas las sociedades son desiguales?”. La desigualdad entre individuos y grupos es, en su opinión, resultado directo de la condición humana -cómo experimentamos respecto del mundo que nos rodea y cómo nos relacionamos con el riesgo- combinado con cómo los juegos de negociación y los mercados tienden a desarrollarse bajo condiciones generales. Pequeñas diferencias en condiciones básicas diferencias que no necesariamente tienen nada que 
ver con el talento o el esfuerzo- se intensificarán a lo largo del tiempo y crecerán sin límite. “El único límite para la acción del jugador mejor posicionado es su propio interés en mantener con vida al otro jugador de manera que la sociedad pueda continuar existiendo" (Molander, 2016: 181).

Para Molander, las disparidades que se aprecian en la realidad no se explican solo por el talento y el esfuerzo. Para él, la pregunta interesante es “¿cómo algunas sociedades tienen éxito en conseguir un nivel decente de igualdad a pesar de la tendencia natural a moverse hacia la desigualdad?". La segunda pregunta es " $¿$ se puede influir en la desigualdad?”. La respuesta para este economista sueco es afirmativa. Así, señala que si observan los índices Gini que miden la desigualdad en los países de la OCDE se aprecian importantes diferencias en países económica y socialmente similares, diferencias que responden a un enfoque político de la cuestión en cada país.

La tercera pregunta es “¿cómo se relacionan las ideologías clásicas con la desigualdad como fenómeno?". Para este autor, el "liberalismo" a menudo ha infravalorado la importancia de tener similares puntos de partida en la vida, de manera que el talento y el esfuerzo puedan ejercer plenamente su influencia. El "conservadurismo" cae en el mismo error, en el caso de que se trate de un error, y tiene problemas de legitimidad para explicar y justificar las diferencias existentes en la distribución de rentas y bienes. La "socialdemocracia" es la ideología que sale mejor parada respecto al objetivo de conseguir una sociedad más igualitaria, principalmente a través de la educación pública, el sistema de la seguridad social, y la política fiscal.

Para Molander "la distancia de una sociedad respecto de la frontera de la desigualdad es una medida de su grado de civilización”. Aboga por una política activa a favor de la distribución. La desigualdad es parte de la condición humana pero se puede influir en ella. La sociedad no es un objeto inanimado; es un artefacto humano. "Con el adecuado diseño y políticas vigilantes, se puede mantener en el aire tan exitosamente como la máquina de volar de los hermanos Wright” (Molander, 2016: 183).

\subsection{Las compresiones periódicas de la desigualdad}

En opinión de Walter Scheidel, profesor de Humanidades, Clásicas e Historia y experto en Biología Humana por la Universidad de Stanford (Estados Unidos) en su libro El Gran Nivelador. Violencia e Historia de la Desigualdad desde la Edad de Piedra hasta el Siglo XXI" (Scheidel, 2018), en la historia de la humanidad las mayores compresiones periódicas de la desigualdad se han debido a alteraciones masivas y violentas del orden establecido, "provocadas por la movilización militar de masas, la revolución transformadora, la desintegración de estados y las pandemias”. Sus efectos "siempre han superado en envergadura a todos los ejemplos conocidos de equiparación por medios enteramente pacíficos”.

Pero, añade Scheidel, “la historia no determina el futuro. Puede que la modernidad sea distinta. Muy a largo plazo, quizá lo sea. Es posible que nos sitúe en una trayectoria hacia la singularidad, un punto en que todos los seres humanos se unan en un superorganismo cuerpo-máquina globalmente interconectado y ya no tengan que preocuparse de la desigualdad. 0 puede que los avances tecnológicos lleven las desigualdades a nuevos extremos separando a una élite biomecánica y genéticamente mejorada de los simples mortales, estos siempre controlados por las capacidades cada vez mayores de sus superiores. 0 también es posible que no ocurra nada de todo esto. Quizá estemos avanzando hacia resultados que ni siquiera podemos concebir”.

"Por ahora estamos atrapados en las mentes y los cuerpos que tenemos y en las instituciones que estos han creado. Esto indica que las perspectivas para una igualación futura son escasas. Será un desafío para las democracias sociales de la Europa continental el mantener y adaptar sistemas elaborados de impuestos elevados y una amplia redistribución o para las democracias más ricas de Asia el preservar su adjudicación inusualmente equitativa de ingresos brutos para contener la creciente marea de desigualdad, que solo puede cobrar más fuerza a medida que la globalización y unas transformaciones demográficas sin precedentes aumentan la presión. No sabemos si podrán resistir: la desigualdad ha ido en aumento en todas partes, una tendencia que sin duda va contra el statu quo".

Continúa señalando Scheidel: “Durante miles de años, la historia ha alternado largos períodos de desigualdad creciente, alta y estable con compresiones violentas. A lo largo de seis o siete décadas, desde 1914 hasta los años setenta u ochenta, tanto las economías ricas como aquellos países que habían caído bajo regímenes comunistas experimentaron algunas de las equiparaciones más intensas de la historia documentada. [...]. Desde entonces, gran parte del mundo ha entrado en lo que podría convertirse en el siguiente gran período prolongado, un regreso a la acumulación permanente de capitales y concentración de ingresos. Si hemos de guiarnos por la historia, una reforma política pacífica podría ser desigual para los desafíos cada vez mayores que se avecinan".

Pero ¿qué hay de las alternativas? "Todos aquellos que valoramos una mayor igualdad económica haríamos bien en recordar que, con las más raras excepciones, siempre ha venido acompañada de tristeza" (Scheidel, 2018: 465-466). Scheidel aboga por aplicar políticas redistributivas para hacer frente al problema creciente de la desigualdad en buena parte del mundo y evitar así los riesgos potenciales de los contextos en los que históricamente se ha visto reducida. 


\subsection{El bienestar común}

En El precio de la desigualdad, Joseph E. Stiglitz, premio Nobel de Economía de 2001 y catedrático de Economía en la Universidad de Columbia (Estados Unidos), plantea una análisis crítico con el devenir de las últimas décadas de las políticas que se vienen aplicando en Estados Unidos que, entre otras cosas, acrecientan la desigualdad y generan una sociedad cada vez más radicalmente dual. Este análisis, con sus correspondientes adaptaciones a otros países del mundo, señala los riesgos que el mantenimiento o el más que probable agravamiento de esta situación, de no alterarse las políticas actualmente dominantes, puede tener para la sociedad estadounidense y propone una serie de medidas que, en su opinión, conseguirían mejorar la eficiencia económica, la equidad y la igualdad de oportunidades.

Un resumen parcial sería el siguiente.

1. Poner coto a los excesos en la parte más alta: poner coto al sector financiero - puesto que una gran parte del aumento de la desigualdad tiene que ver con los excesos del sector financiero, es el lugar más idóneo para iniciar un programa de reformas-; hacer que los bancos sean más transparentes, sobre todo en su trato de los derivados financieros no bursátiles -en palabras de Warren Buffet, "armas financieras de destrucción masiva"-; leyes sobre competencia más estrictas y aplicadas con mayor rigor, etc.

2. Reforma fiscal: avanzar hacia una progresividad real.

3. Ayudar a los demás: mejorar el acceso a la educación; ayudar a los estadounidenses corrientes a ahorrar; atención sanitaria para todos; reforzar otros programas de protección social, etc.

4. Suavizar la globalización: crear un terreno de juego más nivelado y acabar con la "carrera hacia los mínimos".

5. Recuperar y mantener el pleno empleo, a través de una adecuada política monetaria y de las instituciones financieras, corregir los desequilibrios comerciales, etc.

6. Un nuevo pacto social: apoyar la acción colectiva de los trabajadores y ciudadanos; discriminación positiva para eliminar el legado de la discriminación.

7. Recuperar el crecimiento sostenible y equitativo: una agenda para el crecimiento, basada en las inversiones públicas: reorientar la inversión y la innovación para conservar los puestos de trabajo y el medio ambiente, etc.

Por último, propone atacar los problemas a su juicio más urgentes en Estados Unidos - mercado de trabajo y vivienda- $y$ acometer una agenda de reformas políticas para el fortalecimiento de la democracia. En este último sentido, recuerda a Alexis de Tocqueville, quien en su tiempo definió como una característica propia del pueblo estadounidense la de prestar atención al "interés propio bien entendido". No se trata del interés propio en sentido estricto (yo quiero lo que es bueno para mí ahora mismo). El interés propio "bien entendido" es distinto. Significa que prestar atención al interés propio de todo el mundo -en otras palabras, al bienestar común-, en última instancia, es una precondición para el bienestar de uno mismo. Tocqueville lo entendía como un rasgo distintivo del pragmatismo estadounidense. Aquellos astutos estadounidenses comprendían un hecho esencial: preocuparse por los demás no solo es bueno para el alma, es bueno también para los negocios.

Stiglitz advierte de los niveles de desigualdad existentes en su país y en el resto del mundo, y alerta respecto a sus riesgos. Plantea finalmente un dilema respecto al futuro de su país. En una hipótesis puede visualizarse una sociedad cada vez más dividida entre ricos y pobres, y otra en la que la diferencia entre ricos y pobres se reduce, donde hay un sentimiento de destino compartido, un compromiso común con la igualdad de oportunidades y la equidad, donde nos tomamos en serio la Declaración Universal de los Derechos Humanos, que subraya la importancia no solo de los derechos civiles, sino también de los derechos económicos, y no solo de los derechos de propiedad, sino también de los derechos económicos de los ciudadanos corrientes. En esa visión, el bienestar de nuestros ciudadanos -e incluso nuestro crecimiento económico, sobre todo si se mide de la forma adecuada- será mucho mayor del que podemos lograr si nuestra sociedad sigue estando profundamente dividida.

\section{La economía del bien común}

\subsection{Pérdida del poder político a favor del mercado}

En La economía del bien común (Tirole, 2017) el economista francés Jean Tirole, premio Nobel de Economía en 2014, establece dos afirmaciones relevantes. Por un lado, tras exponer que "desde el rotundo fracaso económico, cultural, social y medioambiental de las economías planificadas, desde la caída del muro de Berlín y la metamorfosis económica de China, la economía de mercado ha pasado a ser el modelo dominante, por no decir exclusivo, de organización de nuestras sociedades", Tirole señala que "incluso en el 'mundo libre', el poder político ha perdido su influencia a favor del mercado y de una serie de nuevos actores".

Por otro lado, observa Tirole, la victoria de la economía de mercado solo ha sido una victoria a medias, pues no se ha ganado a la gente. "La supremacía del mercado, que solo cuenta con la confianza de una pequeña minoría de nuestros conciudadanos, se acepta con un fatalismo unido, en algunos casos, a la indignación. Una crítica poco precisa denuncia el triunfo de la economía 
sobre los valores humanistas, un mundo sin piedad ni compasión entregado al interés privado, la desintegración del vínculo social y de los valores ligados a la dignidad humana, el repliegue de lo político y del servicio público, o la falta de sostenibilidad de nuestro medioambiente [...]. Todos estos dilemas resuenan con particular intensidad en el contexto actual marcado por la crisis financiera, el aumento del paro y las desigualdades, la incapacidad de nuestros dirigentes de hacer frente al cambio climático, la fragilidad de la construcción europea, la inestabilidad geopolítica y la crisis de los migrantes que de ella resulta, así como por el auge de los populismos en todo el mundo" (Tirole, 2017: 13-14).

\subsection{Búsqueda del bien común y papel de la economía}

Se pregunta Jean Tirole qué ha sido de la búsqueda del bien común y en qué medida la economía puede contribuir a su realización. Reconoce que este concepto puede requerir de la utilización de juicios de valor, pero confía en que a través de la reflexión intelectual es posible eliminar en parte la arbitrariedad inherente al ejercicio de definir el bien común.

A su juicio, reflexionar a través del método denominado "tras el velo de la ignorancia”, es decir aquel que plantea las preguntas haciendo abstracción del lugar que se ocupa en la sociedad y de los atributos que se poseen: ¿en qué tipo de sociedad me gustaría vivir, sabiendo que podría ser un hombre o una mujer, estar dotado de buena 0 mala salud, haber nacido en el seno de una familia acomodada o pobre, instruida o poco cultivada, atea o creyente, crecer en el centro de París o en Lozére, etc.?

Este modo de interrogarse, en la senda de la larga tradición intelectual, inaugurada en Inglaterra en el siglo XVII por Thomas Hobbes y John Locke, que prosiguió en la Europa continental en el siglo XVIII con Immanuel Kant y Jean Jacques Rousseau (y su contrato social) y que se ha renovado recientemente en Estados Unidos con la teoría de la justicia del filósofo John Rawls y la comparación interpersonal de los bienestares del economista John Harsanyi (Tirole, 2017: 14), puede ser una buena manera de acercarnos a la concepción del bien común.

Para Tirole, la búsqueda del bien común "pasa en gran medida por la creación de instituciones cuyo objetivo sea conciliar en la medida de lo posible el interés individual y el interés general. En este sentido, la economía de mercado no es en absoluto una finalidad. Es, como mucho, un instrumento, y un instrumento muy imperfecto, si se tiene en cuenta la discrepancia que puede haber entre el interés privado de los individuos, los grupos o las naciones y el interés general" (Tirole, 2017: 15). Y continúa argumentando el Nobel de Economía de 2014: "La búsqueda del bien común adopta como criterio nuestro bienestar tras el velo de la ignorancia. No prejuzga soluciones y no tiene mas finalidad que el bienestar colectivo. Admite el uso privado para el bienestar de la persona, pero no el abusar de él a expensas de los demás" (Tirole, 2017: 16).

Para Jean Tirole, “la economía, como las otras ciencias humanas y sociales, no tiene como objetivo sustituir a la sociedad a la hora de definir el bien común. Pero puede contribuir a ello de dos modos. Por una parte, puede orientar el debate hacia los objetivos encarnados en el concepto de bien común diferenciándolos de los instrumentos que pueden contribuir a su realización. [...] y sobre todo, la economía al considerar el bien común como un criterio fundamental, desarrolla los instrumentos para contribuir a él".

\subsection{Estado y mercado, complementarios}

La economía no está ni al servicio de la propiedad privada y los intereses individuales, ni al de los que querrían utilizar al Estado para imponer sus valores o hacer que sus intereses prevalezcan. Rechaza tanto la supremacía del mercado como la supremacía del Estado. La economía está al servicio del bien común; su objetivo es lograr un mundo mejor. Para ello su tarea es identificar las instituciones y políticas que van a favorecer el interés general. En su búsqueda del bienestar para la comunidad, la economía engloba la dimensión individual y la colectiva del sujeto. Analiza las situaciones en las que el interés individual es compatible con esa búsqueda del bienestar colectivo y aquellas en las que, por el contrario, constituye un obstáculo" (Tirole, 2017: 17).

En su libro, Jean Tirole nos dice que "no tenemos que elegir entre Estado y mercado, como nos quieren hacer creer los partidarios del intervencionismo y los del laissez-faire. El Estado y el mercado son complementarios y no excluyentes. El mercado necesita regulación y el Estado, competencia e incentivos. Este economista francés ve así la nueva función de los Estados modernos: “[...] el Estado se transforma en regulador. Su nuevo papel es el de fijar las reglas del juego e intervenir para paliar los fallos del mercado, no el de sustituirlo. Asume todas sus responsabilidades allí donde los mercados son deficientes, para garantizar una competencia sana, regular los monopolios, supervisar el sistema financiero, responsabilizarnos frente al medioambiente, protegernos frente a los avatares de la salud y de nuestra trayectoria vital, crear una auténtica igualdad de oportunidades y redistribuir mediante los impuestos" (Tirole, 2017: 22).

El mensaje de este reconocido economista es optimista. "Los males que sufren nuestras sociedades no son producto de la fatalidad: existen soluciones para el paro, el calentamiento global, el deterioro de la construcción europea”. El hilo conductor que traspasa todos los análisis específicos que ofrece en su obra se apoyan en la teoría de la 
información, innovación fundamental de la economía en las cuatro últimas décadas. Esta teoría se basa en una evidencia: las decisiones de los actores económicos (los hogares, las empresas, el Estado) están coaccionadas por la limitada información de que disponen. Las consecuencias de esas limitaciones informativas se pueden ver en todas partes: en las dificultades de los administrados para comprender y evaluar las políticas de sus gobernantes; en la del Estado para regular bancos y empresas dominantes, para proteger el medioambiente o para gestionar la innovación; en la de los inversores para controlar el uso que hacen de su dinero las empresas que ellos financian; en los modos de organización de nuestras empresas, etc. Para Tirole, "el tema de la información está en el núcleo mismo de la elaboración de nuestras instituciones y de nuestras decisiones en el ámbito de la política económica. En el núcleo del bien común" (Tirole, 2017: 24-25).

\section{Crisis de Europa y su papel en el futuro}

Por la importancia del contexto europeo en el que nos desenvolvemos, traemos aquí el análisis al respecto por parte de tres reconocidos autores.

\subsection{Crisis estructural, multidimensional, y de legitimidad: responder a las necesidades de la ciudadanía}

En su libro Las crisis de Europa (Castells, 2018), Manuel Castells, sociólogo y reputado analista, junto a un amplio elenco de colaboradores, sostiene que la crisis actual, en lo que atañe a Europa, "no es una sola, sino más bien múltiples crisis”, y así “Europa, el Viejo Continente parece bastante incapaz de contener la espiral de desintegración e impotencia" (Castells, 2018: 613).

Si bien hay elementos en la situación actual en Europa que son comunes a otros que se producen a nivel mundial -crisis de legitimidad de las instituciones, desconfianza hacia las élites políticas, etc.- hasta el punto de que su pueden considerar "rasgos emblemáticos de nuestros tiempos", estos "no explican la especificidad de la crisis que envuelve a Europa hoy en día, ni nos ayudan a entender la medida en que la crisis de Europa es una crisis creada por ella misma".

Castells y sus colaboradores establecen la idea de que "las crisis que han aquejado a Europa desde el estallido de la crisis económica y financiera de 2008-
"Las semillas de la crisis se sembraron hace muchos años, durante las décadas de 1980 y 1990, cuando se elaboraban los planes para la unión monetaria" (Castells, 2018: 614).

Para estos autores, "la crisis financiera en Europa [...] tuvo su inicio en la crisis del mercado de hipotecas de alto riesgo que comenzó en Estados Unidos a finales de 2006 y se fue haciendo cada vez más catastrófica en 2007 y 2008". Pero cuando las repercusiones de aquella crisis golpearon a Europa, afectaron a unas instituciones que eran estructuralmente endebles y vulnerables. La prioridad que se concedió a la estabilidad financiera y presupuestaria - una prioridad que reflejaba los principios económicos normativos que han arraigado en las prácticas y en las políticas del actor más poderoso de la UE, Alemania- tuvo graves consecuencias sociales, dado que provocó altos niveles de desempleo y el deterioro de la sanidad pública, sobre todo en los países del sur de Europa. El sufrimiento de una enorme cantidad de gente no es tanto el resultado de la crisis financiera en sí, ni exclusivamente de la crisis financiera: en gran parte se debe a las medidas con las que se pretendía ponerle fin. [...] La crisis de Europa es multidimensional: es económica, financiera, social, y sumamente política, [...] también es cultural, intelectual y moral, y afecta al meollo de los valores que definen a Europa. Así pues, las crisis de Europa forman parte de un proceso acumulativo que es lo bastante fuerte como para cuestionar las instituciones básicas de la Unión Europea, unas instituciones que ya están amenazadas por una creciente falta de legitimidad".

La UE siempre fue un proyecto desde arriba, impulsado por unas élites políticas que compartían una visión particular de una Europa unificada y que llevaron adelante ese proyecto sin esforzarse demasiado por arrastrar consigo a los ciudadanos [...] siempre ha habido un abismo entre las instituciones de la UE que toman las decisiones y los ciudadanos de sus Estados miembros,..., además, a medida que se han ido transfiriendo más y más competencias desde los Parlamentos nacionales al nivel europeo, sin un desarrollo proporcional de los mecanismos de representación y rendición de cuentas, el déficit en términos de responsabilidad democrática ha ido en aumento. [...] La falta de legitimidad se vio exacerbada por la ampliación de Europa, que dificultaba cada vez más que los Estados miembros se unieran en torno a una política común firmemente reivindicada, y provocaba que cada vez fuera más probable que los procesos de toma de decisiones se vieran obstaculizados por intereses encontrados. Eso dificultó la capacidad de la UE para actuar de forma decisiva y flexible ante las crisis que se avecinaban e incrementó la tendencia a claudicar ante unas fuerzas del mercado que socavaban una visión política compartida" (Castells, 2018: 615-617).

Continúa señalando Castells que, "por consiguiente, desde el principio, las instituciones europeas no han sido las más idóneas a efectos de la construcción 
europea. La UE emprendió una ambicioso proyecto de construcción política, buscando muchas instituciones que tuvieran muchas de las características de un Estado, pero en la práctica las instituciones que creó no tenían capacidad de actuar como un Estado. Era, y sigue siendo, un Estado más en sus aspiraciones que en la realidad. [...] Eso fue lo que ocurrió con el euro: las consideraciones económicas quedaron eclipsadas por el objetivo político de poner coto a una Alemania reunificada y de involucrar a los miembros de la unión monetaria en un nuevo ciclo irreversible de integración europea".

Por todo ello, a juicio de Castells y sus colaboradores, "existe un riesgo muy real de que Europa pueda llegar a deshacerse. Muchos de los problemas fundamentales que han sacudido a la UE en los últimos años siguen sin resolverse, incluida la crisis económica que sigue amenazando a la estabilidad en la eurozona. Los estados-nación podrían abandonar la UE uno por uno: el Brexit ha abierto una puerta por la que otros podrían decidir salir. La UE podría escindirse en una Europa del Norte, diferenciada de una Europa del Sur, o una Europa-núcleo al margen de una Europa-periférica. También existe la posibilidad de una Europa a dos velocidades, o incluso a muchas velocidades, que algunos analistas consideran la única forma de evitar la desintegración pura y simple".

"Pero es posible que no llegue a ocurrir lo peor. Se podrían establecer medidas específicas para afrontar los problemas más acuciantes y la UE podría aunar esfuerzos y, una vez más, salir del apuro. Como siempre ocurre en épocas de crisis, las visiones a largo plazo tienden a disolverse en las metas a corto plazo, mientras los responsables de dirigir las instituciones se centran en las exigencias de la supervivencia. Eso dificulta que los actores políticos y sociales afronten las crisis de legitimidad en Europa proponiendo medidas sustanciales y realistas a fin de reconstruir o relanzar el Viejo Continente. [...] Y el futuro de Europa, sea cual sea, es un futuro que pervivirá únicamente si sus instituciones se construyen de una forma que atiendan con más cuidado, y respondan más eficazmente de lo que lo ha hecho la UE hasta ahora, a los deseos, las necesidades y los puntos de vista de su pueblo" (Castells, 2018: 621).

\subsection{Europa en la encrucijada: soberanismo o compartición de riesgos}

Para Jean Tirole, son dos fundamentalmente las posibilidades que pueden identificar el futuro próximo de Europa. Tras analizar los errores y omisiones del proceso de construcción europea hasta la fecha, y en particular el de la creación del euro como moneda común sin el apoyo de medidas que le dieran verdadera fortaleza, este economista cree que son dos las salidas posibles que se presentan en un contexto en el que en Europa: "no se puede insistir a la vez en la soberanía y exigir una mayor compartición de riesgos. En ello radica el fondo del problema"

Por un lado, estaría la opción de seguir con los planteamientos de un Tratado de Maastricht mejorado, "controlando las deudas y déficits públicos y excluyendo, en teoría, los rescates ex ante". Para Tirole, "las tendencias soberanistas actuales juegan, sin lugar a dudas, a favor de la mejora del enfoque maastrichtiano".

Por otro lado, estaría la opción del federalismo, a través de una mayor compartición de riesgos. Para Tirole, "primero es necesario ponerse de acuerdo sobre una base de leyes comunes, como ocurrió, aunque más modestamente, en la fase inicial de la construcción europea y luego en la progresiva creación del denominado 'acervo comunitario"”.

Pero, como señalan los expertos, el federalismo se enfrenta entre otros al problema de los límites de la solidaridad. "Al final, todo depende de la voluntad de las regiones ricas de financiar a las regiones pobres. No se sabe aún bien qué es lo que determina esa voluntad. Está claro que una lengua y un sentimiento nacional común ayudan a generar esas transferencias unidireccionales: es el caso de Alemania o Italia. Una observación clásica dice que el Estado de Bienestar está generalmente más desarrollado en las comunidades homogéneas. [...] nos guste o no, las poblaciones son más proclives a la redistribución cuando los beneficiarios les son cercanos desde el punto de vista cultural, lingüístico, religioso o racial”.

Concluye Tirole que "es difícil prever qué camino emprenderá Europa para resolver sus problemas, quizás una nueva mejora del tratado de Maastricht, acompañada de una serie de formas de integración, específicas, pero obligatoriamente limitadas, del estilo de la unión bancaria. Pero, si los europeos deseamos vivir bajo el mismo techo, debemos aceptar la idea de perder un poco más de soberanía. Y, para lograrlo en esta época de soberanismos, debemos rehabilitar el ideal europeo y permanecer unidos en torno a éste ideal, lo que no es tarea fácil”.

\subsection{Europa: mayor integración y dimensión social}

Por su parte Joaquín Almunia, quien fuera vicepresidente de la Unión Europea entre 2010 y 2014, en su libro Ganar el futuro. Cómo Europa y la socialdemocracia pueden salir juntas de sus crisis (Almunia, 2018) propone una serie de pasos para superar las crisis sufridas por la Unión Europea estos últimos años:

- Aprovechar el cierto optimismo del momento económico actual y las reacciones a favor de Europa a partir del Brexit, de la elección de la actual Administración estadounidense, y la sensación de inseguridad de los ciudadanos europeos ante el terrorismo y los conflictos 
bélicos en nuestras fronteras, para establecer estrategias ambiciosas y viables al tiempo.

- Sumar fuerzas unidos como conjunto para hacer frente a los retos de la globalización y los cambios tecnológicos, en un mundo en el que el peso de Europa continuará descendiendo en la esfera internacional.

- Atender por parte de los líderes europeos y de las instituciones que dirigen la brecha que se ha creado en la opinión pública entre sus aspiraciones y los resultados que tales instituciones vienen ofreciendo. Los esfuerzos de integración quizás deban plantearse a diversas velocidades, utilizando las posibilidades que ofrece el Tratado.

- Mejorar la imbricación de la dimensión política nacional con la comunitaria para acercar la integración a los ciudadanos y mejorar el control democrático de las decisiones por parte de estos.

- Completar la arquitectura institucional de la Unión Económica Monetaria (UEM), así como su abanico de herramientas de actuación. En su opinión, lo más urgente sería avanzar hacia una unión bancaria dotada del pilar que le falta - un sistema común de garantía de depósitos para el conjunto de la eurozona- y de un fondo de respaldo de magnitud suficiente para la resolución de entidades en crisis. El actual Mecanismo Europeo de Estabilidad (MEDE) debe evolucionar hasta convertirse en un Fondo Monetario Europeo.

- La política fiscal de la UEM debe asegurar un nivel adecuado de demanda agregada. Se necesita completar y profundizar el mercado interior en sectores como la energía, la economía digital y los mercados de capitales. La política de cohesión debe ser evaluada y en su caso reorientada para que su impacto sobre la convergencia real de las economías europeas sea mayor que el logrado hasta ahora.

- La mayoría de los ciudadanos no quieren disociar la recuperación de la economía de la preservación del modelo social europeo. No considerarán superada la crisis hasta que sus derechos sociales fundamentales sean protegidos de manera eficaz. Iniciativas como el denominado “pilar social” promovido por la Comisión Europea van encaminadas a retomar la agenda social europea.

- La socialdemocracia debe actualizar sus planteamientos económicos en materia de gastos e ingresos públicos, y en general en lo que se refiere a la gestión macroeconómica, y definir una estrategia que combine mejor eficiencia y equidad y se plantee en un marco europeo.

- Por último, desde España, plantea Almunia que lo europeo ya no puede ser considerado algo ajeno, debiendo ser partícipes activos del proyecto europeo, apostando por su dimensión social, requisito necesario para que la integración recobre su sintonía con los ciudadanos. (Almunia, 2018: 282-288).

\section{Resumen y conclusiones}

Vivimos en una época en la que la tecnología, la globalización económica y el cambio climático interactúan y se refuerzan entre sí de manera crecientemente acelerada. La velocidad del cambio afecta a todo: a cómo producimos, consumimos, nos relacionamos, e impactamos en la naturaleza. También a cómo nos organizamos social y políticamente. El nuevo escenario exige, entre otras medidas, crear nuevas redes de protección social y facilitar a la ciudadanía que pueda aprovechar las oportunidades y reducir el impacto negativo del nuevo ciclo.

Por otra parte, en las últimas décadas se ha alterado el equilibrio de poder entre política y economía, inclinándose a favor del mercado. Ello está acrecentando un reparto desigual de la riqueza, y la insuficiente respuesta de los poderes públicos a ese desafío, está generando una notable desafección de la ciudadanía respecto de sus representantes políticos, generándose nuevos retos para la estabilidad política. La enorme desigualdad entre zonas del mundo y los conflictos en determinadas zonas del mismo, así como las consecuencias del cambio climático, mueven y moverán a millones de personas a migrar, generándose nuevos retos para la sociedades emisoras y receptoras de esa población.

Instituciones supraestatales, como la Unión Europea, sometida a las presiones de las recientes crisis, están demostrando sus insuficiencias de diseño, planteando así incógnitas reales sobre el tipo de eventual futuro de las mismas. En este contexto se recoge, a modo de conclusión, un resumen de las aportaciones de los autores citados.

- Para Thomas L. Friedman, la aceleración de la globalización, de la tecnología, y del cambio climático, exigen nuevos enfoques que tengan en cuenta a las personas y modifiquen nuestra manera de incidir sobre el planeta. El reto en este nuevo escenario reside "en generar redes de protección social y regulaciones gubernamentales que permitan a los ciudadanos aprovechar al máximo estas aceleraciones y amortiguar sus peores efectos". Ello constituiría el verdadero reto de gobernabilidad del mundo.

- En opinión de Naomi Klein, en las últimas décadas se viene produciendo una deliberada campaña desde los sectores más conservadores para denostar la esfera pública. Lo que algunos autores han denominado la Nueva Historia parte de la premisa acuñada en su época por el entonces presidente Reagan de que "el Gobierno es el problema, no la solución”. A partir de ello, poderosos grupos de presión están trabajando a favor de un menor papel de la Administración Pública, de la desregulación, y en definitiva de la jibarización del espacio público. Sustituir el interés colectivo, el bien común, por los intereses de las grandes corporaciones tiene influencia en el incremento de la desigualdad y en la actuación 
dañina respecto al clima en nuestro planeta. En ello se plantea en un horizonte de pocas generaciones un verdadero reto de supervivencia para la humanidad.

- Saskia Sasen, desde la sociología, alerta de las nuevas lógicas sistémicas que surgen de la descomposición de la economía política del siglo $X X$, que fomentan la capacidad de exclusión del actual ciclo económico y político, frente a otros momentos en que el objetivo era la inclusión de personas y sociedades.

- Cathy O’Neill expone los serios riesgos de la influencia de los actuales modelos matemáticos que rigen cada día más infinidad de parcelas de la vida de las personas, y propone la identificación de modelos matemáticos para el bien común, que incorporen decisiones morales para evitar los sesgos de los actualmente existentes que "codifican el pasado e incrementan la desigualdad".

- El economista sueco Per Molander concluye que se puede influir en la desigualdad, al tiempo que posiciona a las distintas tradiciones políticas en referencia a este objetivo, aboga por una política activa a favor de la distribución "con el adecuado diseño y políticas vigilantes”.

- Walter Scheidel, en su análisis sobre la desigualdad a lo largo de la historia, nos dice que esta se ha visto reducida fundamentalmente por causas como las guerras, las revoluciones, el colapso de los Estados y las grandes epidemias. Alerta de los riesgos futuros, a tenor de los hechos históricos, de un incremento de la desigualdad, y defiende el reto democrático de la redistribución a través de la actuación política pacífica.

- Joseph E. Stiglitz propone una agenda de reformas económicas y políticas para que las políticas dominantes no atiendan, como en su opinión hacen en la actualidad, a los intereses de los absolutamente más ricos del planeta, y por el contrario trabajen a favor de la mejora de la eficiencia económica, la equidad y la igualdad de oportunidades para el conjunto de los ciudadanos. Stiglitz alerta de los riesgos para el equilibrio de las sociedades de avanzar en la actual senda de políticas que favorecen la desigualdad y no atienden a los intereses de las mayorías sociales.

- Jean Tirole defiende el papel de la economía como instrumento para el logro del bien común, proponiendo el método de reflexión "a través del velo de la ignorancia" - ¿en qué tipo de sociedad me gustaría vivir, sabiendo que puedo ser un hombre o una mujer, estar dotado de buena o mala salud, haber nacido en el seno de una familia acomodada o pobre, instruida o poco cultivada, atea o creyente, urbana o rural, etc.?-. Tirole sostiene la complementariedad del Estado y el mercado - el mercado necesita regulación y el Estado, competencia e incentivos-. La tarea de la economía es identificar las instituciones y políticas que van a favorecer el interés general.

En cuanto al papel de Europa, se recogen opiniones de tres autores:

- El sociólogo Manuel Castells y un reputado elenco de colaboradores, exponen las deficiencias de diseño del entramado europeo que hacen que Europa tenga una insuficiencia estructural para dar respuesta a las diversas crisis - económicofinanciera; social; y política- que la azotan. Esas deficiencias de diseño, restan legitimidad a la Unión Europea y plantean serios riesgos sobre el futuro del Viejo Continente. En su opinión sólo a partir de la respuesta a las necesidades de las mayorías sociales Europa puede tener un futuro esperanzador.

- Para Jean Tirole, se plantean dos posibles escenarios a futuro: soberanismo o compartición de riesgos, inclinándose por avanzar en esta segunda vía. Su visión del futuro no es fatalista, y defiende la eficacia de las medidas que se pueden adoptar para la solución de los males que aquejan a las sociedades modernas. "Los males que sufren nuestra sociedades no son producto de la fatalidad: existen soluciones para el paro, el calentamiento global, el deterioro de la construcción europea".

- Por último, Joaquín Almunia apuesta por un futuro más integrado en la Unión Europea, trazado con ambición y realismo, y que para conseguir retomar la confianza de la ciudadanía, subraye la dimensión social del proyecto europeo.

De las opiniones de estos autores cabe concluir, en esta era de las aceleraciones, la necesidad de modificar las políticas actualmente dominantes y generar nuevas estrategias que con seriedad y urgencia aborden el reto de la protección del medio ambiente y den respuesta a las necesidades de la ciudadanía, a fin de asegurar, en todo el mundo, la sostenibilidad económica, medioambiental, y política, de las sociedades. 


\section{Bibliografía referenciada}

ALMUNIA, J. (2018): Ganar el futuro. Cómo Europa y la socialdemocracia pueden salir juntas de sus crisis, Taurus.

CASTELLS, M. (2018): Las crisis de Europa, Alianza.

FRIEDMAN, T.L. (2018): Gracias por llegar tarde, Deusto.

KLEIN, N. (2017): Decir NO no basta, Paidós.

MOLANDER, P. (2016): The Anatomy of Inequality, Melville House.
O’NEILL, C. (2017): Armas de Destrucción Matemática, Capitán Swing.

SASSEN, S. (2015): Expulsiones. Brutalidad y complejidad en la economía global, Katz.

SCHEIDEL, W. (2018): El Gran Nivelador, Crítica.

STIGLITZ, J.E. (2012): El precio de la desigualdad, Debolsillo.

TIROLE, J. (2017): La economía del bien común, Taurus. 